\title{
CAR CRASH ANALYSIS - A REVIEW
}

\section{A. MURTAZA}

Professor, Amity School of Engineering \& Technology, Amity University, Lucknow Campus, Uttar Pradesh, India

ABSTRACT
Passive vehicle crash tests have been standardized for crashworthiness analysis. Additional safety equipment is
also incorporated to protect occupants. Pre-crash braking is able to reduce the severity of accident. Anti-collision device
and emergency operations make use of controlling speed or stopping before collision in railway operation. Potential of
pre-crash braking needs to be analysed further.
KEYWORDS: Car Crash, Collision, Crashworthiness, Simulation, Dummies \& Pre-Crash Braking

Received: Feb 21, 2019; Accepted: Mar 13, 2019; Published: Apr 17, 2019; Paper Id.: IJMPERDJUN201933

\section{INTRODUCTION}

The ability of a vehicle's structure to protect its occupants during an impact is known as crashworthiness. The structure of an automobile is such that, it absorbs impact energy by controlled plastic deformation in controllable manner and preserves a space for survival. In addition, airbags, anti-lock braking system and traction control are being used as safety features. Vehicle crash tests [1] are conducted to assess the safety of occupants and pedestrians.

Crash Simulation is a way to test the crashworthiness of the car body virtually by using various simulation software. The advantage of crash simulation over real crash is that the same model can be used again and again to check the different parameters involved in crash analysis with different materials and scenarios.

Important parameters are steering wheel intrusions, occupant space and the occupants subjected to deceleration levels. These are governed by legal crash simulation regulations. Crash simulation to create real life situation also include use of crash test dummies and passive safety devices such as seat belts, air bags,

shock absorbers, Anti-lock brake system and dash board.

The types of crash test [1] that is conducted in the present day by different assessment programs for assessing crashworthiness worldwide is given table 1 .

Table 1: Programs for Assessing Crashworthiness

\begin{tabular}{|c|l|l|}
\hline S. No. & \multicolumn{1}{|c|}{ Region } & \multicolumn{1}{c|}{ Name } \\
\hline 1 & Europe & EuroNCAP (New Car Assessment Program) \\
\hline 2 & USA & NHTSA (National Highway Traffic Safety Administration) \\
\hline 3 & Australia, New Zeeland & ANCAP \\
\hline 4 & Latin America & LATIN NCAP \\
\hline 5 & China & C-NCAP \\
\hline 6 & Germany & ADAC (Allgemeiner Deutcher Automobil-Club). \\
\hline
\end{tabular}


Various conditions of test include a vehicle and an obstacle or between two vehicles. The collision can be frontal, side and rear. To assess injury of occupant dummies are used. Test speed ranges are from $29 \mathrm{kmph}$ (18mph) to 64kmph (40mph).

\section{TESTS AND SIMULATIONS}

Mnyazikwiye et al [2] and Pawlus et al [3] have used mathematical models and estimated physical parameters (stiffness and dampers). Models were validated with experimental results from real crash tests. Jain et al [4, 5] have done the crash simulation on Ansys v14. The analysis included use of different materials. Full frontal impact simulation was done at a speed of $33.33 \mathrm{~m} / \mathrm{s}$; the parameters predicted were total deformation, elastic strain and equivalent stress. They concluded that the Steel V-250 has the maximum stress and polycarbonate gave the least value.

Ambati et al [6] have simulated a frontal impact of a Chevrolet C1500 pick-up truck model, moving with a velocity of $56.3 \mathrm{kmph}$ in to a rigid immovable barrier. They used LS-DYNA for this simulation. In this simulation, the bumper, engine and the rails absorbed most of the energy before the wheel impacts the wall, and half the energy of the crash is absorbed by these components after about $0.04 \mathrm{sec}$ of the crash initiation. In this simulation, two models were used. Model 1 was similar to physical test model of NCAC (National Crash Analysis Centre) model and model 2 had lighter material. Figure 1 shows energy balance graphs. Maximum value of K.E. was $239.126 \mathrm{~kJ}$ for model 1 and $208.30 \mathrm{~kJ}$ for model 2. Deceleration vs. time variations is shown in figure 2. The maximum value of deceleration for model 1 and model 2 were $98.94 \mathrm{~g}$ and $84.83 \mathrm{~g}$, respectively. Variation of velocity with time is shown in figure 3 .

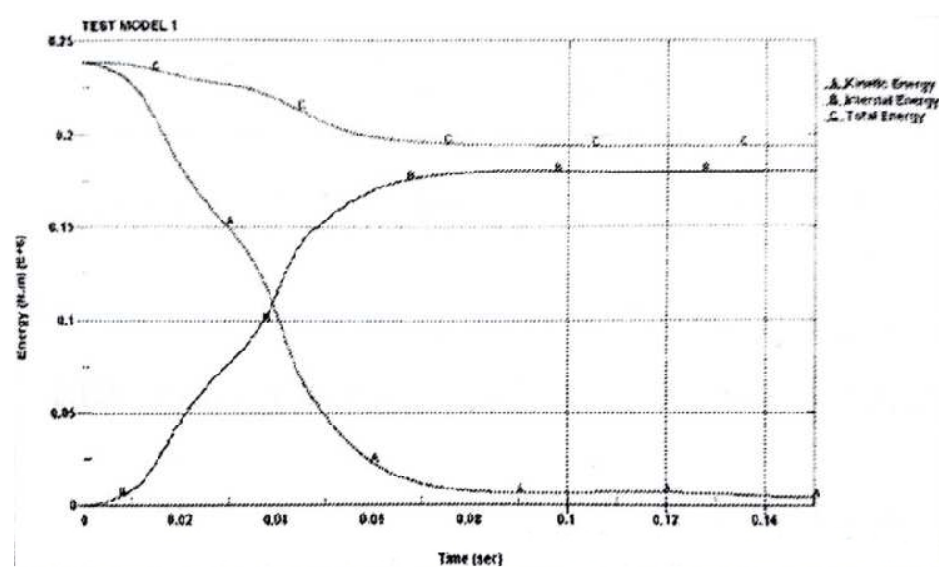

Figure 1: Kinetic Energy, Internal Energy Variation During Crash [6] of Model 1

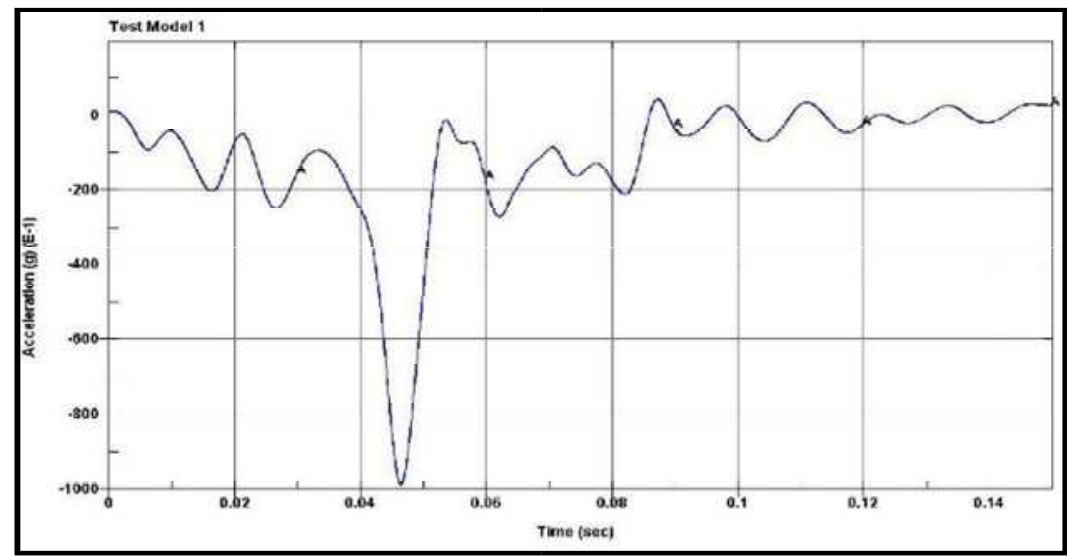

Figure 2: Acceleration vs. Time for Model 1 [6] 


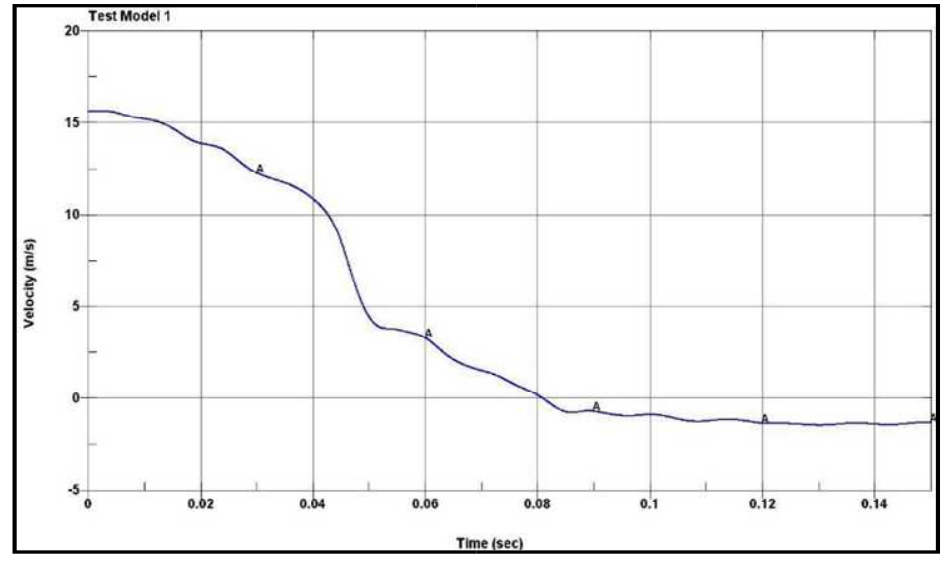

Figure 3: Velocity vs. Time for Model 1 [6]

Andrew and Xiao [7] modeled 2002 Ford Explorer and simulated crash in Ansys. Incoming speeds used were from $20 \mathrm{mph}$ to $100 \mathrm{mph}$ in increments of $20 \mathrm{mph}$. The total forces and the maximum deformations after impact at various speeds are shown in figure 4.

Total deformation at $20 \mathrm{mph}$ was 10.9”, but nothing that would cause any harm to occupant. Whereas, a crash at 100mph will leave a car totaled and will result in fatality as shown in Figure 5. The length of this vehicle was 180" and deformation was 73.44", which is about $40 \%$ of the total length. Discovery channel's Myth Busters performed a real impact test on a car, similar to this simulation. In Myth busters' car testing, a car travelled at 100mph into a wall. These results, at impact, show that the car nearly deformed half of its length.

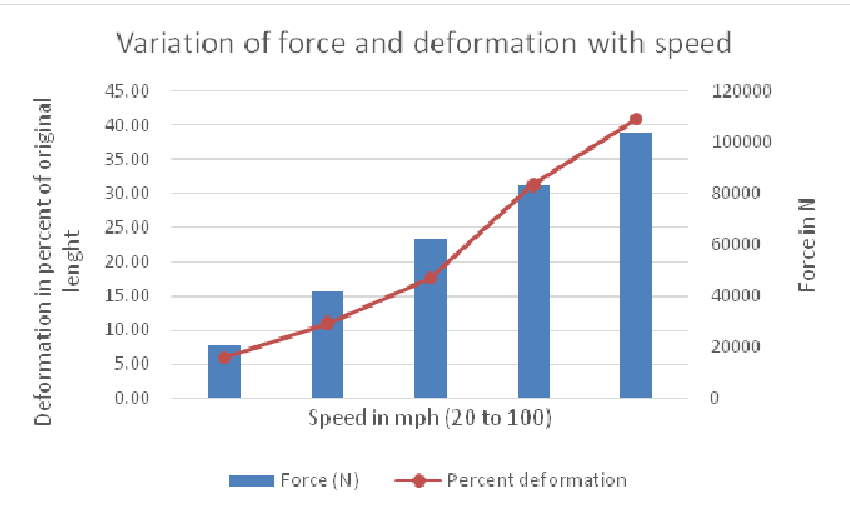

Figure 4: Force Magnitudes and Maximum Deformations at Various Car Speeds

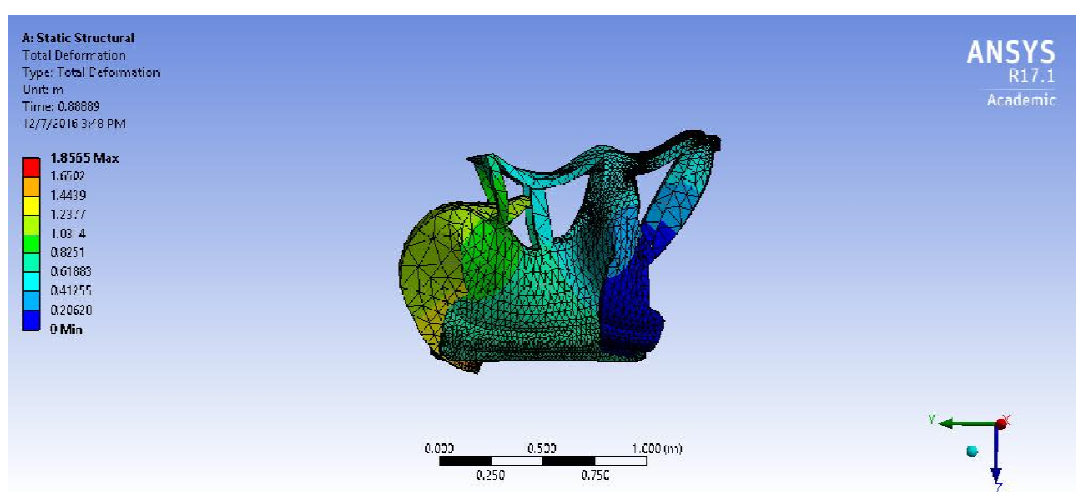

Figure 5: Total Deformation of Car at $100 \mathrm{kmph}$ [7] 


\section{PRE-CRASH BRAKING [8]}

In the foregoing paragraphs, the entire crash analysis considers a driver, a passive system. Crash tests serve [8] to test and evaluate the passive safety of a vehicle, covering deformation zones, occupant cell as well as the seat belts and airbags, whereas, a driver in actual practice is an active member of the system, who attempts to use steering and brakes to avoid or reduce the impact of an accident. Drivers and passengers crash response behavior is important. In order to be able to reproducibly test and evaluate the effects of relevant systems in crash tests according to the holistic approach of integrated safety, the pre-crash reactions of the vehicle must be initiated in a realistic manner, well before the impact with the barrier.

\subsection{Anti-Collision System on Railways}

On railways [9], which are a guided vehicle and an engine driver does not use steering, are equipped with anti-collision devices to automatically brake or control the speed. One typical system is shown in figure 6; it relies on GPS satellites for positioning updates.

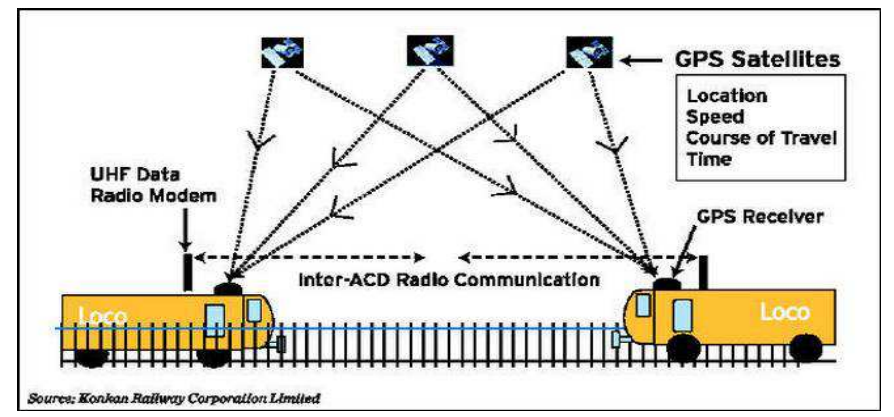

Figure 6: Anti-Collision Device Systems [9]

The active safety features such as effect for stability and braking(ESC and BAS) are analysed in separate driving tests. So, no other standard for tests exists on the extended effect of active safety systems on passive systems.

\subsection{Effect of Pre-Crash Braking [8]}

Table 2: Effect of Deceleration on Velocity and Kinetic Energy

\begin{tabular}{|c|c|c|}
\hline $\begin{array}{c}\text { Deceleration } \\
\mathbf{m} / \mathbf{s} / \mathbf{s}\end{array}$ & $\begin{array}{c}\text { Velocity } \\
\mathbf{m} / \mathbf{s}\end{array}$ & $\begin{array}{c}\text { Kinetic Energy } \\
\mathbf{k J}\end{array}$ \\
\hline 0 & 64 & 332 \\
\hline 1 & 60.4 & 296 \\
\hline 2 & 56.8 & 261 \\
\hline 3 & 53.2 & 229 \\
\hline 4 & 49.6 & 199 \\
\hline 5 & 46 & 171 \\
\hline 6 & 42.4 & 145 \\
\hline 7 & 38.8 & 121 \\
\hline 7.8 & 35.92 & 104 \\
\hline 8 & 35.2 & 100 \\
\hline 9 & 31.6 & 81 \\
\hline 9.81 & 28.684 & 67 \\
\hline 10 & 28 & 64 \\
\hline 11 & 24.4 & 48 \\
\hline 12 & 20.8 & 35 \\
\hline 13 & 17.2 & 24 \\
\hline
\end{tabular}




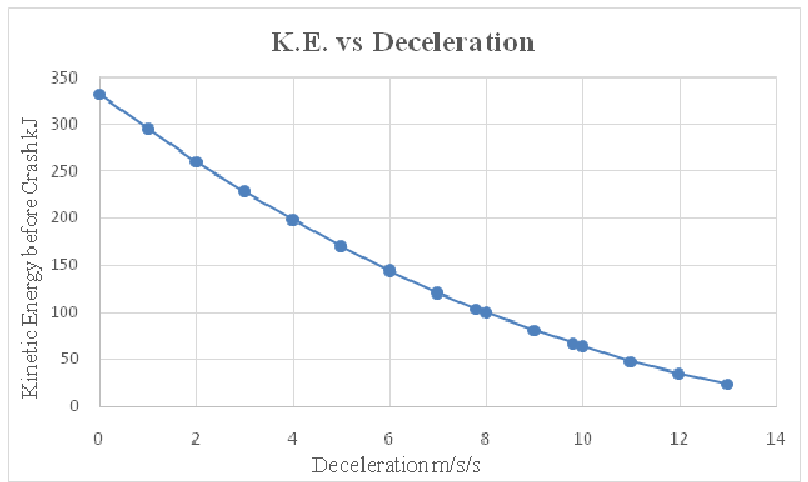

Figure 7: Variation in Kinetic Energy with Pre-Crash Braking

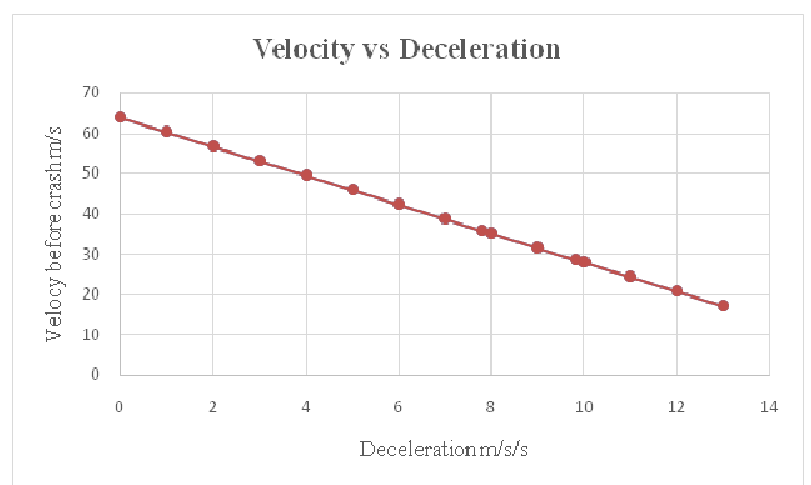

Figure 8: Variation in Velocity Due to Different Level of Deceleration

A moving vehicle possesses kinetic energy, and the severity of a road accident depends on it. Therefore, pre-crash braking can reduce kinetic energy and also the severity of accident. Table 3 gives the variation of velocity for various values of deceleration acting 1 second before the crash and corresponding velocity. Initial velocity before braking is taken $64 \mathrm{kmph}$. It also shows the corresponding kinetic energy for a vehicle of mass 2,100 kgs. These are shown in figures $7 \& 8$.

Reduction in kinetic energy due to pre-crash braking is equivalent to virtual deformation zone [8] and remaining is absorbed by mechanical deformation zone.

\subsection{Frontal Impact Test with Pre-Crash Braking[8]}

This test was conducted according to Euro NCAP (unbraked) with a starting speed of $64 \mathrm{kmph}$ and $40 \%$ overlap with a vehicle having a mass of 2,164 kg. Belted dummies were used for driver and front passenger. Emergency braking was initiated 0.9 seconds before crash. It reduced the speed from $64 \mathrm{kmph}$ to $40.4 \mathrm{kmph}$ and corresponding reduction in kinetic energy was from $352 \mathrm{~kJ}$ to $136 \mathrm{~kJ}$ before collision with the barrier. There was a lateral deviation of $2 \mathrm{~mm}$ and dipping of impact point by $35 \mathrm{~mm}$ due to braking.

\subsubsection{Occupant Injury[8]}

Pre-crash braking has reduced the speed resulting in reduction in kinetic energy before impact. It resulted in the reduction in head injury of driver by $76 \%$ and passenger by $78 \%$. It was due to $22 \%$ deceleration of driver dummy and $47 \%$ for front passenger dummy.

\subsection{Tests with A-HBM [10]}

Simulated tests were conducted [10]with active human body model (called SAFER A-HBM). It had the capability 
to simulate emergency braking events before a crash event. There was a reduction in accelerations by $15-45 \%$,in case of occupant dummy and 60-70\% by pre-braking from $64 \mathrm{~km} / \mathrm{h}$ to $56 \mathrm{~km} / \mathrm{h}$ and $39 \mathrm{~km} / \mathrm{h}$, respectively.

\section{CONCLUSIONS}

Pre-crash braking affects the severity of impact. Deceleration level reduction causing injury has come down, appreciably. This aspect has not been considered in any of the standards. In rail transport, anti-collision device working in emergency conditions at controlled speed of $15 \mathrm{kmph}$ are in vogue.

Simulation and experimental work needs to be done on reducing the effect during crash, which will enhance the safety of the occupants.

\section{REFERENCES}

1. A.I. Radu, C. Cofaru, 'Study of Current State of crash testing', Bulletin of the Transilvania University of Brasvo, Vol. 8 (57) No.2-2015, Series I: Engineering Sciences.

2. B.B. Mnyazikwiye, H.R. Karimi, K.G. Robbresmyr; Mathematical modelling of a vehicle frontal crash by double spring-massdamper model; 2013 XXIV International Conference on Information, communication and automation technologies (ICAT), October 30 - November 01, 2013.

3. W. Pawlus, J.E. Nielsen, H.R. Karimi, K.G. Robbersmyr; Mathematical modelling and Analysis of a vehicle crash; Proceedings of the 4thEuropean Computing Conference; ISSN: 1790-5117, ISBN: 978-960-474-178-6; PP194-199.

4. Car crash impact test in Ansys workbench 14.5 Explicit dynamics https://www.youtube.com/watch? $v=g M B S k y x Z O A g \& t=68$ s.

5. A. Jain, A. Gour, C.R. Kaushik, A Bhandralia; Crashworthiness of the vehicle body on material optimization using autodynsolver; International Journal of Engineering Applied Sciences and Technology, 2016; Vol. 1, Issue 9, ISSN No. 2455-2143.

6. T. Ambati, K.V.N.S Srikanth, P. Veerearaju; Simulation of vehicular frontal crash-test; International Journal of Applied Research in Mechanical Engineering (IJARME) ISSN: 2231 -5950, Volume-2, Issue-1, 2012.

7. Andrew Hickey, Shaoping Xiao, 'Finite Element Modeling and Simulation of Car Crash', International Journal of Modern Studies in Mechanical Engineering, Volume 3, Issue 1, 2017. Pp 1-5.

8. A. Berg, Peter Rucker, Christian Domsch, 'Presentation and Discussion of a Crash Test using a car with Automatic Pre-Crash Braking', http://citeseerx.ist.psu.edu/viewdoc/download?doi=10.1.1.682.8641\&rep=rep1\&type=pdf

9. Anti-collision Device: http://www.konkanrailway.com/sites/default/files/ACD\%20presentation-e-march13_0.pdf

10. Merete Ostmann, Lotta Jakobsson, '.An examination of pre-crash braking influence on occupant crash response using active human body model', IRCOBI Conference 2016, IRC-16-37.pp 275-283. 